Difficult Decisions

\title{
Early stage Hodgkin's disease in adults: which is the correct treatment?
}

\section{Michael Brada}

The Institute of Cancer Research and The Royal Marsden Hospital, Downs Road, Sutton, Surrey, UK.

Hodgkin's disease (HD) is considered by many to be a curable malignancy. If good prognosis patients are selected and treated appropriately the cure rate is high. Inappropriate or incorrect treatment may at best inflict unnecessary toxicity and at worst compromise survival.

The current treatment options are radiotherapy, chemotherapy and combined radiotherapy and chemotherapy (combined modality therapy; CMT). The aim of treatment is cure with least toxicity and the choice is influenced by technical issues of the disease and therapy and by individual patient considerations. The following discussion does not attempt to give a route map for the clinician. It is to provide a guide through the complexities of early HD and a rational basis for patient management.

\section{Staging}

Early Hodgkin's disease can be defined by Ann Arbor criteria $^{1}$ as clinical (CS) or pathological stage (PS) I and II, which describes nodal disease confined to one side of the diaphragm.

Initial stage is determined by clinical examination, mapping all sites of palpable disease and the size of involved nodes. Mediastinal, hilar and lung parenchymal disease are best assessed by chest X-ray and thoracic computed tomographic (CT) scan. Abdominal disease is detected by CT scanning which has taken over the role of lymphography. The comparison of the two techniques suggests a higher sensitivity and overall accuracy for lymphography. ${ }^{2}$ The experience in this procedure is declining with increasing reliance on CT scanning and lymphography is only carried out in selected, usually CT negative patients. The role for magnetic resonance imaging (MRI) and high dose gallium scanning is not yet clearly defined.

Correspondence: M. Brada, B.Sc., M.R.C.P., F.R.C.R., Department of Radiotherapy \& Oncology, The Royal Marsden Hospital, Downs Road, Sutton, Surrey, SM2 5PT, UK.

Received: 25 April 1989
Splenic disease and lymph node involvement above the superior mesenteric artery are notoriously difficult to visualize with standard imaging techniques. Staging laparotomy and splenectomy detect occult HD at these sites in approximately a third of CS I and II patients. $^{3}$

It has become clear that splenectomy has no therapeutic value and the surgical procedure itself has no influence on survival, ${ }^{4-7}$ although findings at laparotomy to some extent define prognosis. In addition, surgery carries a significant morbidity, ${ }^{8}$ and splenectomy is associated with increased risk of overwhelming septicaemia, particularly in children (for review see reference 9) and a suggestion of a higher risk of leukaemia. ${ }^{10}$ Laparotomy is, therefore, not justified simply to detect occult disease, particularly if the results do not influence the treatment decision. If pathological staging information is still required, the likelihood of abdominal involvement can be estimated from presenting clinical features. The incidence of occult abdominal disease is related to site and size of nodes in CS I disease in the neck and age, sex, histology and number of involved sites in CS I and II disease.,11

Diagnosis of liver involvement is difficult and relies on clinical examination, abnormal liver function tests and liver imaging with CT scan or ultrasound. The correlation between biochemistry, imaging and true pathological involvement is not satisfactory and occasional biopsy for histological confirmation may be required.

\section{Treatment toxicity}

Large radiation fields are used in extended field radiotherapy ('mantle' or 'inverted Y') but the dose necessary to control disease is relatively low (35-45 Gy). ${ }^{12,13}$ With appropriate shielding of the lungs and a large portion of the heart the incidence of transient pneumonitis is low and there is no significant cardiac toxicity. Detailed studies of lung and cardiac function report some measurable changes, mostly without symptomatic deficit. ${ }^{14-16}$ Infradiaphragmatic irradiation is associated with an increased risk of gastro- 
intestinal disturbance, which is dose-related with low incidence with radiation doses under $35 \mathrm{~Gy} .{ }^{17,18}$ Providing the gonads are outside the irradiated field fertility is preserved. The incidence of second malignancy following radiotherapy alone is low. The risk of acute leukaemia is not increased, ${ }^{19-21}$ though the risk of developing a solid tumour may be higher, particularly following a very long period of observation. ${ }^{22,23}$

This contrasts with chemotherapy which carries a higher risk of early and late toxicity. Chemotherapyinduced myelosuppression predisposes to infection. $^{24}$ MOPP (mustine, vincristine, procarbazine, prednisolone) and its variants such as ChLVPP (chlorambucil, vinblastine, procarbazine, prednisolone) have a sterilizing effect and most men, and the majority of women, become infertile. This is particularly distressing in HD, where a large proportion of patients are young. The use of chemotherapy is also associated with increased risk of acute leukaemia ${ }^{19,20}$ and solid tumours. However, newer chemotherapy regimens such as ABVD (adriamycin, bleomycin, vinblastine, DTIC) have a lesser risk of second malignancy and infertility. ${ }^{25}$

\section{Prognostic factors}

The 10 year survival of patients with PS and CS I and II HD is $60-90 \%$ with $50-80 \% 10$ year disease-free survival. Although important, Ann Arbor staging is no longer sufficient to define prognosis, as the behaviour of Hodgkin's disease is also related to other tumour and host characteristics.

The analysis of factors which determine prognosis depends on the therapy used and the end point studied and must take into account initial staging. Success of first-line treatment in controlling disease can be tested by its ability to prevent recurrence. The suggested actuarial measure is time to treatment failure which is described in the literature as freedom from progression, progression-free or disease-free survival (DFS). ${ }^{26}$ Prognostic factors for DFS are therefore clinical features which in some way relate to the ability of primary therapy to control disease.

Patients with Hodgkin's disease are often salvaged with second-line therapy and an analysis of survival is therefore a measure of the effectiveness of both primary and salvage treatment and their toxicity. Hence prognostic factors for survival are patient and disease parameters which influence disease control by a mixture of treatments.

Independent prognostic factors for DFS are shown in Table I. Tumour burden is the most common determinant of recurrence after radiotherapy. It is variously defined by the size of involved nodes (bulky if $>5$ or $10 \mathrm{~cm}$ in diameter), the number of nodal sites of disease, combination of both and the size of
Table I Prognostic factors in early stage Hodgkin's disease - disease-free survival

\begin{tabular}{|c|c|c|c|}
\hline Stage & Therapy & $\begin{array}{l}\text { Independent adverse } \\
\text { prognostic factors }\end{array}$ & Reference \\
\hline PS IA-IIB & RT vs $\mathrm{CMT}^{*}$ & $\begin{array}{l}\text { Bulk } \\
\text { B symptoms } \\
\text { RT alone }\end{array}$ & 40 \\
\hline PS I-IIIA & RT & $\begin{array}{l}\text { Mediastinal bulk } \\
\text { Number of sites } \\
\text { Sex } \\
\text { Elevated ESR }\end{array}$ & 41 \\
\hline PS I \& II & RT & Mediastinal bulk & 42 \\
\hline CS I \& II & $\begin{array}{l}\text { ChT vs } \\
\text { CMT* }^{*}\end{array}$ & $\begin{array}{l}\text { Bulk } \\
\geqslant 2 \text { sites } \\
\text { Age }>45\end{array}$ & 33 \\
\hline PS I \& II & RT vs $\mathrm{CMT}^{*}$ & $\begin{array}{l}\text { Tumour burden } \\
\text { Male sex } \\
\text { Histology } \\
\text { RT alone }\end{array}$ & 43 \\
\hline CS I \& II & RT & $\begin{array}{l}\text { Stage II \& B } \\
\text { Mediastinal bulk } \\
\text { Age } \\
\text { Histology }\end{array}$ & 44 \\
\hline CS I \& II & RT \& CMT & $\begin{array}{l}\text { B symptoms \& ESR } \\
\geqslant 3 \text { sites } \\
\text { Sex }\end{array}$ & 6 \\
\hline PS I \& II & $\mathbf{R T}$ & $\begin{array}{l}\text { Mediastinal bulk } \\
\geqslant 3 \text { sites }\end{array}$ & 45 \\
\hline
\end{tabular}

*Randomized studies; $\mathrm{RT}=$ radiotherapy; $\mathrm{ChT}=$ chemotherapy; CMT = combined modality therapy.

mediastinal mass (bulky mediastinal disease is usually over $1 / 3$ of transverse thoracic diameter on a PA chest radiograph). Presence of B symptoms, the level of ESR and gender are also of prognostic importance in studies which employ chemotherapy and radiotherapy. ${ }^{6}$ Although histology has occasionally been reported as a determinant of DFS a re-analysis of European Organization for Research and Treatment of Cancer (EORTC) randomized studies did not find a histological subtype to be of prognostic significance. ${ }^{27}$ Patients with limited early stage disease therefore achieve a good long term disease control following extended field radiotherapy alone.

By far the most important prognostic factor determining survival is age (Table II). This has been shown in studies of early disease as well as advanced disease $^{28,29}$ and in a large cohort of Pattern of Care 
study. ${ }^{30}$ Older patients ( $>40$ and $>60$ years) have worse prognosis and this is independent of therapy. Other factors have also been reported to influence survival and they include histology and a measure of the extent of disease or tumour burden (Table II). In many instances they are the same as prognostic factors for DFS but their significance in terms of survival is less than age.

Prognosis in early Hodgkin's disease represents a continuum and the division into good and poor prognosis is to some extent arbitrary. The rationale for this separation is to define two treatment groups radiotherapy and chemotherapy or CMT. This avoids toxicity of chemotherapy in patients who have good

Table II Prognostic factors in early stage Hodgkin's disease - survival

\begin{tabular}{|c|c|c|c|}
\hline Stage & Therapy & $\begin{array}{l}\text { Independent adverse } \\
\text { prognostic factors }\end{array}$ & Reference \\
\hline PS IA-IIB & $\mathrm{RT}$ vs $\mathrm{CMT}^{*}$ & $\begin{array}{l}\text { Bulk } \\
\text { PSIII } \\
\text { B symptoms }\end{array}$ & 40 \\
\hline CS I-II & RT & $\begin{array}{l}\text { Age } \\
\text { Histology } \\
\text { ESR } \\
\text { Sex } \\
\text { Mediastinal involve- } \\
\text { ment }\end{array}$ & 7 \\
\hline CS I \& II & RT \& CMT & $\begin{array}{l}\text { Age } \\
\text { Stage } / \geqslant 3 \text { sites }\end{array}$ & 46 \\
\hline PS I - IIIA & RT & $\begin{array}{l}\text { Age } \\
\text { Symptoms } \\
\text { Number of sites }\end{array}$ & 41 \\
\hline PS I \& II & RT & $\begin{array}{l}\text { Age } \\
\text { (Histology) }\end{array}$ & 42 \\
\hline CS I \& II & CT vs CMT* & $\begin{array}{l}\text { Age } \\
\text { Bulk }\end{array}$ & 33 \\
\hline PS I \& II & $\mathrm{RT}$ vs CMT* & $\begin{array}{l}\text { Age } \\
\text { Tumour burden }\end{array}$ & 43 \\
\hline CS I \& II & RT & $\begin{array}{l}\text { Age } \\
\text { Stage } \\
\text { Histology }\end{array}$ & 44 \\
\hline CS I \& II & RT \& CMT & $\begin{array}{l}\text { Age } \\
\text { Sex } \\
\text { Histology } \\
\geqslant 4 \text { sites }\end{array}$ & 6 \\
\hline
\end{tabular}

*Randomized study; RT = radiotherapy; $\mathrm{ChT}=$ chemotherapy; CMT = combined modality therapy. prognosis following radiotherapy alone reserving chemotherapy or CMT for patients with poor prognosis disease. The exact position of the dividing line is a subject of endless discussion among oncologists but a reasonable objective basis is to define an acceptable level of DFS following radiotherapy alone. It would seem a simple concept but it is difficult to apply in practice as each study differs in the details of therapy and selection criteria. The EORTC Group have selected $\leqslant 20 \%$ recurrence rate as acceptable following radiotherapy with a good prognostic group therefore defined as $\geqslant 80 \%$ DFS.

Most studies which base their treatment decision on prognostic characteristics have also incorporated prognostic factors for survival which test both initial and salvage treatment. The usual assumption in the treatment policy is that poor prognosis patients (i.e. those with worse survival) will benefit from more aggressive therapy and at present there is little evidence to substantiate it. As the most important prognostic factor for survival is age, such a policy may lead to elderly patients receiving the most aggressive treatment.

A number of prognostic indices of various degree⿻上丨 of complexity are described in publications listed io Tables I and II. The specific prognostic index musp relate to staging and treatment strategies used $t \&$ generate it. A good prognosis group in generat includes patients with small tumour burden such as $C S^{2}$ I, CS II with less than 3 sites of disease, non-bulky peripheral and mediastinal disease and in patients wit favourable histology (lymphocyte predominant? nodular sclerosis), combination of low ESR and absence of B symptoms. The poor prognostic category usually includes patients with one or more adverse features.

\section{Treatment strategies}

Ideally each prognostic category should be subject to a prospective randomized study testing the effectiveness and toxicity of two or more treatments. The recognition of prognostic factors has been a gradual process of increasing sophistication. Older randomized studies did not have the benefit of the present knowledge, yet only long-term results give a true picture of the disease.

Prospective randomized trials comparing radiotherapy with CMT in early Hodgkin's disease have been summarized recently. ${ }^{31}$ All have shown a disease-free survival advantage for CMT, but none demonstrated an improvement in survival. Retrospective stratification has also failed to show a survival advantage in a poor prognosis subgroup, although the disease control with radiotherapy alone is often inadequate. Only a recently published review of EORTC 
group experience suggests that a small subset of patients with poor prognosis disease may benefit in terms of survival from initial chemotherapy. ${ }^{6}$

Three randomized studies in early stage Hodgkin's disease have compared chemotherapy alone with either radiotherapy or CMT. Early results of an Italian study suggest a worse disease control with MOPP compared to radiotherapy. ${ }^{32}$ An Argentinian study which included a large proportion of children suggests that COPP (cyclophosphamide, vincristine, procarbazine, prednisolone) chemotherapy is equally effective in good prognosis disease when compared to CMT ${ }^{33}$ However, CMT had shown DFS and a slight survival advantage in poor prognosis early disease. A preliminary report of an NCI study comparing MOPP with radiotherapy shows no difference in survival. Although the recurrence rate was lower in the MOPP arm it was accompanied by higher toxicity. ${ }^{34}$

The studies indicate that radiotherapy is the treatment of choice in good prognosis early stage Hodgkin's disease. On the present evidence it is not justified to use MOPP type chemotherapy as first line treatment in these patients.

Although there is no overall survival advantage for CMT in patients with unfavourable prognostic characteristics (with a possible exception noted above) the recurrence rate after extended field radiotherapy is unacceptably high. These patients should be considered for chemotherapy or CMT. If chemotherapy were used as first line treatment the question which has not yet been answered is the additional role of radiotherapy. Retrospective studies show that involved field radiotherapy adds little toxicity and is effective at controlling disease. Addition of radiotherapy in stage III disease improves disease-free survival ${ }^{28,35}$ and is therefore likely to carry the same benefit in poor prognosis early stage disease. An improvement in survival from this approach is yet to be demonstrated.

Individual categories within early stage Hodgkin's disease are known to be associated with a particularly high risk of recurrence within the initially involved site. This is true for patients with bulky mediastinal disease treated with radiotherapy or chemotherapy alone and it is reasonable to treat these patients with CMT.

The treatment decision must take into account not only the probability of relapse but also individual considerations such as the importance of retaining fertility and the psychological stress induced by the need for close surveillance if a high risk of relapse is anticipated. If the philosophy of therapy is to use the most effective treatment initially with low risk of relapse, chemotherapy should be employed first. In a young patient where the preservation of fertility is important it may be reasonable to opt for treatment of lesser efficacy, such as radiotherapy. If chemotherapy is considered unavoidable, men should be offered sperm storage.

\section{New treatment approaches}

The commonest site of recurrence following radiotherapy is outside the irradiated field and this can be to some extent alleviated by the addition of chemotherapy even in good prognosis disease. It would be desirable to reduce recurrence rate to a minimum providing the toxicity of chemotherapy was low. There have been two approaches to reducing chemotherapy toxicity - reducing the number of chemotherapy courses and substituting MOPP by a non-toxic combination.

Three courses of MOPP chemotherapy followed by radiotherapy is an effective approach but the longterm toxicity is not yet clear. ${ }^{36-38}$ Early results of a small randomized study of VBM (vinblastine, bleomycin, methotrexate) chemotherapy and involved field radiotherapy compared with extended field radiotherapy are encouraging. Addition of ${ }^{0}$ 을 chemotherapy has improved DFS with no survival $\overrightarrow{\mathbb{N}} \vec{z}$ difference between the two arms. ${ }^{39}$ Providing the toxicity remains low, the combination of non-toxic chemotherapy and limited irradiation may point to the future direction in the management of early Hodgkin's disease. Although it is not justified to use MOPP as the initial treatment in adults with favourable prognosis early stage Hodgkin's disease this does not apply in children where radiotherapy may induce defects of growth and development.

\section{Conclusion}

With the help of prognostic indicators it is possible to separate patients with early Hodgkin's disease into good and poor prognostic groups. The recommended treatment for good prognosis patients is extended field radiotherapy and for poor prognosis patients either chemotherapy alone or CMT. The treatment decision must take into account not only prognostic parameters, but also individual patient considerations such as the risk of infertility and the stress of possible recurrence and salvage therapy. With the introduction of non-toxic chemotherapy regimens it may be possible to limit both the amount and toxicity of chemotherapy and reduce the extent of radiation. At present we have to await longer term results before embarking on such a policy. Although the rationale of treatment strategies is simple the details are complex. The rarity and complexity of this disease make it important that patients are entered into new studies so 
that progress can be maintained. There is no doubt that suboptimal treatment in inexperienced hands compromises the final outcome.

\section{References}

1. Carbone, P.P., Kaplan, H.S., Musshoff, K., Smithers, D.W. \& Tubiana, M. Report of the committee on Hodgkin's disease staging. Cancer Res 1971, 31: 1860-1861.

2. Castellino, R.A. Hodgkin's disease: practical concepts for the diagnostic radiologist. Radiology 1986, 159: 305-310.

3. Brada, M., Easton, D.F., Horwich, A. \& Peckham, M.J. Clinical presentation as a predictor of laparotomy findings in supradiaphragmatic stage I and II Hodgkin's disease. Radiother Oncol 1986, 5: 15-22.

4. Gomez, G.A., Stutzman, L., Reese, P.A. et al. Staging laparotomy with splenectomy in stage I and II Hodgkin's disease. In: Cavalli, F., Bonadonna, G. \& Rozencweig, M. (eds) Malignant Lymphomas and Hodgkin's Disease: Experimental and Therapeutic Advances, chapter 11. Martinus Nijhoff, Boston, 1985, pp. 371-377.

5. Tubiana, M., Hayat, M., Henry-Amar, M., Breur, K., van der Werf-Messing, B \& Burgers, M. Five-year results of the E.O.R.T.C. randomised study of splenectomy and spleen irradiation in clinical stages I and II of Hodgkin's disease. Eur J Cancer 1981, 17: 355-363.

6. Tubiana, M., Henry-Amar, M., Carde, P. et al. Toward comprehensive management tailored to prognostic factors of patients with clinical stages I and II in Hodgkin's disease. The EORTC Lymphoma Group Clinical Trials: 1964-1987. Blood 1989, 73: 47-56.

7. Haybittle, J.L., Easterling, M.J., Bennett, M.H. et al. Review of British national lymphoma investigation studies of Hodgkin's disease and development of prognostic index. Lancet 1985, i: 967-972.

8. Green, D.M., Ghoorah, J., Douglass, H.O. et al. Staging laparotomy with splenectomy in children and adolescents with Hodgkin's disease. Cancer Treat Rev 1983, 10: 23-38.

9. Feld, R. \& Sutcliffe, S.B. Immune deficiency and infectious complications of Hodgkin's disease. In: Selby, P. \& McElwain, T.J. (eds) Hodgkin's Disease, chapter 12. Blackwell Scientific Publications, Oxford, 1987, pp. 301-338.

10. Cartei, G., Cendron, R., Pappagallo, G.L., Aversa, S.M.L. \& Fiorentino, M.V. Splenectomy in Hodgkin's disease: A possible relationship with second acute leukemia. (Abstr) Third International Conference on Malignant Lymphoma, Lugano. 1987, June 10-13 p. 89.

11. Leibenhaut, M.H., Hoppe, R.T., Efron, B., Halpern, J., Nelsen, T. \& Rosenberg, S.A. Prognostic indicators of laparotomy findings in clinical stage I-II supradiaphragmatic Hodgkin's disease. $J$ Clin Oncol 1989, 7: 81-91.

12. Timothy, A.R., Van Dyk, J. \& Sutcliffe, S.B. Radiation therapy for Hodgkin's disease. In: Selby, P. \& McElwain, T.J. Hodgkin's Disease, chapter 9. Blackwell Scientific Publications, Oxford, 1987, pp. 181-249.

\section{Acknowledgements}

I gratefully acknowledge the untiring assistance of Miss $\mathbf{J}$. Saunders and Mrs T. Haynes in the preparation of this manuscript. Professor A. Horwich and Professor P. Selby provided helpful comments and criticism.

13. Schewe, K.L., Reavis, J., Kun, L.E. \& Cot, J.D. Total dose, fraction size and tumour volume in the local control of Hodgkin's disease. Int J Radiat Oncol Biol Phys 1988, 15: 25-28.

14. Green, D.M., Gingell, D.L., Pearce, J. et al. The effect of mediastinal irradiation on cardiac function in patients treated during childhood and adolescence for Hodgkin's disease. J Clin Oncol 1987, 5: 239-245.

15. Smith, L.M., Mendenhall, N.P., Cicale, M.J. et al. Results of a prospective study evaluating the effects of mantle irradiation on pulmonary function. Int $J$ Radiat Oncol Biol Phys 1989, 16: 79-84.

16. Watchie, J., Coleman, C.N., Raffin, T.A. et al. Minimal long-term cardiopulmonary dysfunction following treatment for Hodgkin's disease. Int J Radiat Oncol Biol Phys 1987, 13: 517-524.

17. Gallez-Marchal, D., Fayolle, M., Henry-Amar, M., Le Bourgeois, J.P., Rougier, P. \& Cosset, J.M. Radiation injuries of the gastrointestinal tract in Hodgkin's diseases the role of exploratory laparotomy and fractionation Radiother Oncol 1984, 2: 93-99.

18. Coia, L.P. \& Hanks, G.E. Complications from large field intermediate dose infradiaphragmatic radiation: An analysis of the pattern of care outcome studies for Hodgkin's disease and seminoma. Int J Radiat Oncol Bia $\bar{~}$ Phys 1988, 15: 29-35.

19. Tucker, M.A., Coleman, C.N., Cox, R.S., Varghese, A. \& Rosenberg, S.A. Risk of second cancers after treatment for Hodgkin's disease. $N$ Engl J Med 1988, 318: 76-81.

20. Pedersen-Bjergaard, J., Larsen, S.O., Struck, J. et al. Risk of therapy-related leukaemia and preleukaemia after Hodgkin's disease. Lancet 1987, ii: 83-88.

21. Colman, M. \& Selby, P. Second malignancies and Hodgkin's disease. In: Selby, P. \& McElwain, T.J. (eds) Hodgkin's Disease, chapter 14. Blackwell Scientific Publications, Oxford, 1987, pp. 361-377.

22. Curtis, R.E. \& Boice Jr. J.D., Second cancers after radiotherapy for Hodgkin's disease. (Letter). $N$ Engl $J$ Med 1988, 319: 244-245.

23. Henry-Amar, M. Quantitative risk of second cancer in patients in first complete remission from early stages of Hodgkin's disease. NCI Monographs 1988, no.6: 65-71.

24. Longo, D.L., Young, R.C., Wesley, M. Twenty years of MOPP therapy for Hodgkin's disease. J Clin Oncol 1986, 4: $1295-1306$.

25. Valagussa, P., Santoro, A., Fossati-Bellani, F., Banfi, A. \& Bonadonna, G. Second acute leukemia and other malignancies following treatment for Hodgkin's disease. $J$ Clin Oncol 1986, 4: 830-837.

26. Dixon, D.O., McLaughlin, P., Hagemeister, F.B. et al. Reporting outcomes in Hodgkin's disease and lymphoma. J Clin Oncol 1987, 5: 1670-1672. 
27. Culine, S., Henry-Amar, M., Diebold, J. et al. Relationship of histological sybtypes to prognosis in early stage Hodgkin's disease: A review of 312 cases in a controlled clinical trial. Eur J Cancer Clin Oncol 1989, 25: $551-556$.

28. Brada, M., Ashley, S., Nicholls, J. et al. Stage III Hodgkin's disease - long-term results following chemotherapy, radiotherapy and combined modality therapy. Radiother Oncol 1989, 14: 185-198.

29. Terblanche, A.P.S. Falkson, G. \& Matzner, L. The prognostic significance of age in patients with advanced Hodgkin's disease. Eur J Cancer Clin Oncol 1988, 24: 1805-1809.

30. Kennedy, B.J., Loeb Jr. V., Peterson, V.M., Donegan, W.L., Natarajan, N. \& Mettlin, C. National survey of patterns of care for Hodgkin's disease. Cancer 1985, 56: 2547-2556.

31. Horwich, A. \& Peckhan, M.J. Combined chemotherapy and radiotherapy in the management of adult Hodgkin's disease: indications and results. In: Selby, P. \& McElwain, T.J. (eds) Hodgkin's Disease, chapter 10. Blackwell Scientific Publications, Oxford, 1987, pp. 250-268.

32. Biti, G.P., Gonini, L., Cimino, G. et al. Radiotherapy vs chemotherapy in patients with early stage Hodgkin's disease (Path.St. I and IIA) - Report after 4.5 years of follow-up. (Abstr). Third International Conference on Malignant Lymphoma, Lugano 1987, June 10-13 p.30.

33. Pavlovski, S., Maschio, M., Santarelli, M.T. et al. Randomized trial of chemotherapy versus chemotherapy plus radiotherapy for stage I-II Hodgkin's disease. J Natl Cancer Inst 1988, 80: 1466-1473.

34. Longo, D., Glatstein, E., Young, R. et al. Randomised trial of MOPP chemotherapy $v s$ subtotal nodal radiation therapy in patients with laparotomy documented early stage Hodgkin's disease. Proceedings of ASCO 1987, 6: 206.

35. Grozea, P.N., DePersio, E.J., Coltman, C.A. et al. Chemotherapy alone $v s$. combined modality treatment for stage III Hodgkin's disease: a eight year follow-up of SWOG study No. 7518. (Abstr). Third International Conference on Malignant Lymphoma, Lugano 1987, June 10-13 p. 91.

36. Ferme, C., Teillet, F., D'Agay, M.F. et al. Combined modality in Hodgkin's disease: comparison of six versus three courses of MOPP with clinical and surgical restaging. Cancer 1984, 54; 2324-2329.
37. Zittoun, R., Audebert, A., Hoerni, B. et al. Extended versus involved fields irradiation combined with MOPP chemotherapy in early stages of Hodgkin's disease. J Clin Oncol 1985, 3: 207-214.

38. Lagarde, P., Eghbali, H., Bonickon, F. et al. Brief chemotherapy associated with extended field radiotherapy in Hodgkin's disease. Long-term results in a series of 102 patients with clinical stages I-IIIA. Eur J Cancer Clin Oncol 1988, 24: 1191-1198.

39. Horning, S.J., Hoppe, R.T., Hancock, S.L. \& Rosenberg, S.A. Vinblastine, bleomycin, and methotrexate: an effective adjuvant in favorable Hodgkin's Disease. J Clin Oncol 1988, 6: 1822-1831.

40. Anderson, H., Deakin, D.P., Wagstaff, J. et al. A randomised study of adjuvant chemotherapy after mantle radiotherapy in supradiaphragmatic Hodgkin's disease PS IA-IIB: a report from the Manchester lymphoma group. Br J Cancer 1984, 49: 695-702.

41. Lee, C.K.K., Aeppli, D.M., Bloomfield, C.D. \& Levitt, S.H. Hodgkin's disease: a reassessment of prognostic factors following modification of radiotherapy. Int $J$ Radiat Oncol Biol Phys 1987, 13: 983-991.

42. Mauch, P., Tarbell, N., Weinstein, H. et al. Stage IA and IIA supradiaphragmatic Hodgkin's disease: prognostic factors in surgically staged patients treated with mantle and paraaortic irradiation. J Clin Oncol 1988, 6: 1576-1583.

43. Specht, L., Nordentoft, A.M., Cold, S., Clausen, N.T. \& Nissen, N.I. Tumor burden as the most important prognostic factor in early stage Hodgkin's disease. Cancer 1988, 61: 1719-1727.

44. Sutcliffe, S.B., Gospodarowicz, M.K., Bergsagel, D.E. et al. Prognostic groups for management of localized Hodgkin's disease. J Clin Oncol 1985, 3: 393-401.

45. Verger, E., Easton, D., Brada, M., Duchesne, G. \& Horwich, A. Radiotherapy results in laparotomy-staged Hodgkin's disease. Clin Radiol 1988, 39: 428-431.

46. Horwich, A., Easton, D., Nogueira-Costa, R., Liew, K.H., Colman, M. \& Peckham, M.J. An analysis of prognostic factors in early stage Hodgkin's disease. Radiother Oncol 1986, 7: 95-106. 